QUEIROZ, Yury Augusto dos Santos; GARCIA, Denise Schmitt Siqueira. Deslocados ambientais: um conceito ainda desconhecido. Revista Eletrônica Direito e Política, Programa de Pós-Graduação Stricto Sensu em Ciência Jurídica da UNIVALI, Itajaí, v.10, n.1, edição especial de 2015. Disponível em: www.univali.br/direitoepolitica - ISSN 1980-7791.

\title{
DESLOCADOS AMBIENTAIS: UM CONCEITO AINDA DESCONHECIDO
}

\author{
ENVIRONMENTAL DISPLACED: A CONCEPT STILL UNKNOWN
}

\author{
Yury Augusto dos Santos Queiroz ${ }^{1}$ \\ Denise Schmitt Siqueira Garcia²
}

SUMÁRIO: Introdução; 1. Deslocados ambientais e seus vários conceitos; 2. Deslocados ambientais no conceito do projet de convention relative au statut internationaldes déplacés environnementaux; Considerações finais; Referências das fontes citadas.

RESUMO: O presente trabalho desenvolve um estudo acerca dos diversos conceitos doutrinários e legais inerentes às pessoas que são forçadas a deslocarse por conta de fatores ambientais. O objetivo do presente trabalho é apresentar uma breve exposição dos conceitos de refugiados e deslocados ambientais, tentando buscar principalmente um consenso entre eles. Posteriormente será apresentado resumidamente o que vem a ser o Projeto de Convenção sobre Deslocados Ambientais que foi elaborado sob o comando de Michel Prieur. Através do cruzamento das informações entende-se que deslocados ambientais é todo ser humano que se vê obrigado a deslocar-se de uma região para outra, de um país para outro ou mesmo de continente. Metodologia empregada, na Fase de Investigação foi utilizado o Método Indutivo, no Tratamento de Dados o Método Cartesiano, e, com base na lógica Indutiva. Nas fases da Pesquisa, foram acionadas as Técnicas do Referente, da Categoria, do Conceito Operacional e da Pesquisa Bibliográfica.

Palavras-Chave: deslocados ambientais; refugiados; minorias;

\footnotetext{
1 Advogado, com graduação pelaUniversidade do Vale do Itajaí -UNIVALI, campus Balneário Camboriú. Colaborador do grupo de pesquisa e extensão PAIDEIA (BC). E-mail yury.queiroz@hotmail.com.

2 Doutora pela Universidade de Alicante na Espanha. Membro do grupo de pesquisa Estado, Direito Ambiental, Transnacionalidade. Pesquisadora do projeto de pesquisa intitulado: Possibilidades e limites da avaliação ambiental estratégica no Brasil e impacto na gestão ambiental portuária. Advogada. E-mail: denisegarcia@univali.br
} 
QUEIROZ, Yury Augusto dos Santos; GARCIA, Denise Schmitt Siqueira. Deslocados ambientais: um conceito ainda desconhecido. Revista Eletrônica Direito e Política, Programa de Pós-Graduação Stricto Sensu em Ciência Jurídica da UNIVALI, Itajaí, v.10, n.1, edição especial de 2015. Disponível em: www.univali.br/direitoepolitica - ISSN 1980-7791.

ABSTRACT: This paper develops a study about various concepts doctrinal and legal, inherent the people who are forced to move because of changing environmental factors. The object of this paper is presents a brief summary of the concepts of refugees and displaced environmental, mainly trying to get a consensus. After that will be briefly presented which is the Draft Convention on Environmental Displaced which was prepared under the Michel Prieur command. Through the crossing of information we have that environmentally-displaced is every human being who is forced to move from one region to another, from one country to another or even continent. Methodology used in Phase Research was used Inductive Method in the Data Processing Cartesian method, and based on logic Indutiva. Nas stages of research, the techniques were driven the Referent, the category of the Operational Concept and Research Bibliographic.

Keywords: environmental displaced; refugees; minorities;

\section{INTRODUÇÃO}

O presente tema é atual e seu estudo de relevante importância, pois crescente é o número de desastres naturais em todo o globo, o que tem contribuído com o aumento das discussões sobre as soluções para amenizar estes fatores, porém também é necessário que seja discutido, estudado e analisado a situação das pessoas que são afetadas por estes desastres, pois muitas são obrigadas a deixar sua casa, família e muitas vezes o próprio país em busca de uma melhor condição de vida.

Nesse sentido antes de qualquer outra coisa é extremamente necessário que seja definido o conceito de quem são os deslocados ambientais ou refugiados ambientais, pois mesmo com toda a doutrina e legislação estudada é nítido que ainda não se chegou a um denominador comum.

Portanto como objetivo principal do presente trabalho é apresentar alguns dos vários conceitos que se fazem presentes na doutrina e na legislação, para posteriormente traçar uma breve análise do Projeto de Convenção sobre Deslocados Ambientais que foi elaborada sob o comando de um dos pioneiros no tema, o doutrinador Michel Prieur.

Ao final será elaborado um paralelo entre todos os conceitos chegando a um denominador comum, que faz com que todos apesar de divergentes conduzem 
QUEIROZ, Yury Augusto dos Santos; GARCIA, Denise Schmitt Siqueira. Deslocados ambientais: um conceito ainda desconhecido. Revista Eletrônica Direito e Política, Programa de Pós-Graduação Stricto Sensu em Ciência Jurídica da UNIVALI, Itajaí, v.10, n.1, edição especial de 2015. Disponível em: www.univali.br/direitoepolitica - ISSN 1980-7791.

ao fator crucial e que deve ser defendido sempre independentemente das diferenças que são suscitadas pelos doutrinadores.

Quanto à Metodologia empregada, registra-se que, na Fase de Investigação ${ }^{3}$ foi utilizado o Método Indutivo ${ }^{4}$, na Fase de Tratamento de Dados o Método Cartesiano ${ }^{5}$, e, com base na lógica Indutiva.

Nas diversas fases da Pesquisa, foram acionadas as Técnicas do Referente ${ }^{6}$, da Categoria ${ }^{7}$, do Conceito Operacional ${ }^{8}$ e da Pesquisa Bibliográfica ${ }^{9}$.

Essas são as propostas deste trabalho. A observação de um tema novo, complexo e ainda um tanto indefinido quanto às suas soluções e que necessita de uma abordagem desprovida de qualquer preconceito, deixando aberta a reflexões sobre o que for exposto.

\section{DESLOCADOS AMBIENTAIS E SEUS VÁRIOS CONCEITOS}

É imperioso que se tenha em mente que na maior parte da doutrina sobre o tema base deste trabalho, muitas vezes os termos "deslocados ambientais" e "refugiados ambientais" se confundem e causam enorme confusão na cabeça daqueles que tentam conceituá-los.

\footnotetext{
3"[...] momento no qual o Pesquisador busca e recolhe os dados, sob a moldura do Referente estabelecido [...]. PASOLD, Cesar Luiz. Metodologia da pesquisa jurídica: teoria e prática. 11 ed. Florianópolis: Conceito Editorial; Millennium Editora, 2008. p. 83.

4 "[...] pesquisar e identificar as partes de um fenômeno e colecioná-las de modo a ter uma percepção ou conclusão geral [...]". PASOLD, Cesar Luiz. Metodologia da pesquisa jurídica: teoria e prática. p. 86 .

${ }^{5}$ Sobre as quatro regras do Método Cartesiano (evidência, dividir, ordenar e avaliar) veja LEITE, Eduardo de oliveira. A monografia jurídica.5 ed. São Paulo: Revista dos Tribunais, 2001. p. 2226.

6 "[...] explicitação prévia do(s) motivo(s), do(s) objetivo(s) e do produto desejado, delimitando o alcance temático e de abordagem para a atividade intelectual, especialmente para uma pesquisa." PASOLD, Cesar Luiz. Metodologia da pesquisa jurídica: teoria e prática. p. 54.

7 "[...] palavra ou expressão estratégica à elaboração e/ou à expressão de uma idéia."PASOLD, Cesar Luiz. Metodologia da pesquisa jurídica: teoria e prática.p. 25.

8 "[...] uma definição para uma palavra ou expressão, com o desejo de que tal definição seja aceita para os efeitos das idéias que expomos [...]". PASOLD, Cesar Luiz. Metodologia da pesquisa jurídica: teoria e prática. p. 37.

"Técnica de investigação em livros, repertórios jurisprudenciais e coletâneas legais. PASOLD, Cesar Luiz. Metodologia da pesquisa jurídica: teoria e prática. p. 209.
} 
QUEIROZ, Yury Augusto dos Santos; GARCIA, Denise Schmitt Siqueira. Deslocados ambientais: um conceito ainda desconhecido. Revista Eletrônica Direito e Política, Programa de Pós-Graduação Stricto Sensu em Ciência Jurídica da UNIVALI, Itajaí, v.10, n.1, edição especial de 2015. Disponível em: www.univali.br/direitoepolitica - ISSN 1980-7791.

Os refugiados na concepção tradicional do termo segundo a ACHNUR - United Nations High Commissioner for Refugees ${ }^{10}$, estaria intimamente ligado ao que define a Convenção de Genebra e por este motivo não poderia ser aplicado o mesmo termo aos "refugiados ambientais" face ao da possibilidade de haver confusão terminológica que fosse prejudicial. Vejamos a definição da Convenção ${ }^{11}$ :

Art. $1^{0}$ - Definição do termo "refugiado"

A. Para os fins da presente Convenção, o termo "refugiado" se aplicará a qualquer pessoa:

1) Que foi considerada refugiada nos termos dos Ajustes de 12 de maio de 1926 e de 30 de junho de 1928, ou das Convenções de 28 de outubro de 1933 e de 10 de fevereiro de 1938 e do Protocolo de 14 de setembro de 1939, ou ainda da Constituição da Organização Internacional dos Refugiados;

As decisões de inabilitação tomadas pela Organização Internacional dos Refugiados durante o período do seu mandato, não constituem obstáculo a que a qualidade de refugiados seja reconhecida a pessoas que preencham as condições previstas no parágrafo 2 da presente seção;

2) Que, em consequência dos acontecimentos ocorridos antes de $1^{\circ}$ de janeiro de 1951 e temendo ser perseguida por motivos de raça, religião, nacionalidade, grupo social ou opiniões políticas, se encontra fora do país de sua nacionalidade e que não pode ou, em virtude desse temor, não quer valer-se da proteção desse país, ou que, se não tem nacionalidade e se encontra fora do país no qual tinha sua residência habitual em consequência de tais

\footnotetext{
"Especially UNHCR sees the use of "refugee" critically, underlining that it has a specific meaning in international law as defined by the Geneva Convention. UNHCR therefore fears that using "refugee" may undermine systems currently in place to provide protection to refugees". GREENS EFA Position Paper - Climate Change Refugees and Migration. Redigida por Hélène Flautre, Jean Lambert, Ska Keller and Barbara Lochbihler. Adotado em Maio de 2013. Disponível em: <http://barbara-lochbihler.de/cms/upload/PDF_2013/Greens_EFA_Position Paper_Climate_ChangeRefugeesandMigration.pdf >. Acesso em: 26 Set. 2014.

${ }^{11}$ Adotada em 28 de julho de 1951 pela Conferência das Nações Unidas de Plenipotenciários sobre o Estatuto dos Refugiados e Apátridas, convocada pela Resolução n. 429 (V) da Assembléia Geral das Nações Unidas, de 14 de dezembro de 1950. Entrou em vigor em 22 de abril de 1954, de acordo com o artigo 43. Série Tratados da ONU, No 2545, Vol. 189, p. 137. Disponível em: <http://www.acnur.org/t3/fileadmin/scripts/doc.php?file=t3/fileadmin/Documentos

/portugues/BDL/Convencao_relativa_ao_Estatuto_dos_Refugiados>. Acesso em: 26 Set. 2014.
} 
QUEIROZ, Yury Augusto dos Santos; GARCIA, Denise Schmitt Siqueira. Deslocados ambientais: um conceito ainda desconhecido. Revista Eletrônica Direito e Política, Programa de Pós-Graduação Stricto Sensu em Ciência Jurídica da UNIVALI, Itajaí, v.10, n.1, edição especial de 2015. Disponível em: www.univali.br/direitoepolitica - ISSN 1980-7791.

acontecimentos, não pode ou, devido ao referido temor, não quer voltar a ele.

Como pode ser notada a definição da Convenção de Genebra sobre os refugiados não engloba as mudanças climáticas como um fato causador da condição de refugiado. Todavia há autores que consideram os refugiados apenas um grupo dentro de uma categoria mais ampla de migrantes ${ }^{12}$ e que a crítica feita não possui razão, pois que em linhas gerais são os refugiados definidos por Thelma Thais Cavarzere:

[...] o movimento em si, ou seja, a circulação de pessoas, seja dentro do território, constituindo assim movimento migratório interior, seja para fora dele, caracterizando o movimento migratório exterior ou internacional. E por imigração, a ação de vir estabelecer-se num país estrangeiro, antônimo de emigração. Emigração, ou ato de emigrar, significa saída da pátria em massa ou isoladamente $\mathrm{e}^{13}$.

Assim, como migrante, não importa o fato gerador. Ocorre que essa diferenciação serve para que as políticas nacionais e internacionais a serem cridas, possam ser mais específicas e direcionadas, pois somente dessa forma se poderão atender adequadamente essas populações.

Por outro lado, a definição acima é um tanto simplória quando comparada a outras, vejamos como as Pessoas Internamente Deslocadas (PIDs) ou

\footnotetext{
${ }^{12} \mathrm{Os}$ refugiados pertencem à categoria dos migrantes forçados, que também compreende: solicitantes de refúgio/asilo, deslocados internos, repatriados, reassentados. Segundo Alexander Betts, há dois grandes grupos de migrantes que carecem de efetiva proteção e compõem a categoria dos chamados "migrantes vulneráveis": no primeiro grupo, a necessidade de proteção resulta das condições do país de origem que não estão relacionadas a conflito ou perseguição, como, por exemplo, as mudanças climáticas, a degradação ambiental, os desastres naturais ou as graves dificuldades econômicas e sociais (colapso estatal); no segundo grupo, a demanda de proteção ocorre durante o processo de movimentação, circulação ou deslocamento, momento em que as violações de direitos humanos são praticadas. O autor verifica, nesses casos, que os instrumentos de proteção aos direitos humanos existentes não garantem uma resposta efetiva à demanda de proteção, em virtude, principalmente, da ausência de uma divisão clara de responsabilidades entre as organizações internacionais de proteção e de orientação aos Estados na aplicação desses instrumentos em relação a essa categoria específica de migrantes. BETTS, Alexander. Towards a 'soft law' frame work for the protection of vulnerable migrants. UNHCR Working Paper no 162, p. 23. Disponível em: <http://www.un.org/esa/population/meetings/seventhcoord2008/Betts_SoftLaw__Paper.pdf.> Acesso em: 29 jul 2014.
}

${ }^{13}$ CAVARZERE, Thelma Thais. Direito internacional da pessoa humana: a circulação internacional de pessoas. Rio de Janeiro: Renovar, 1995, p. 09. 
QUEIROZ, Yury Augusto dos Santos; GARCIA, Denise Schmitt Siqueira. Deslocados ambientais: um conceito ainda desconhecido. Revista Eletrônica Direito e Política, Programa de Pós-Graduação Stricto Sensu em Ciência Jurídica da UNIVALI, Itajaí, v.10, n.1, edição especial de 2015. Disponível em: www.univali.br/direitoepolitica - ISSN 1980-7791.

Deslocadas Internas (DIs), são definidas com base nos Princípios Orientadores relativos aos Deslocados Internos ${ }^{14}$ adotados pelas Nações Unidas em 1998:

[...] Os deslocados internos são pessoas, ou grupos de pessoas, forçadas ou obrigadas a fugir ou abandonar as suas casas ou seus locais de residência habituais, particularmente em consequência de, ou com vista a evitar, os efeitos dos conflitos armados, situações de violência generalizada, violações dos direitos humanos ou calamidades humanas ou naturais, e que não tenham atravessado uma fronteira internacionalmente reconhecida de um Estado.

Nessa linha de pensamento importante trazer a baila o conceito do El-Hinnawi, que explica:

Em um sentido amplo, todas as pessoas deslocadas podem ser descritas como refugiados ambientais, dado que foram forçadas a sair de seu habitat original (ou saíram voluntariamente) para se protegerem de danos e/ou para buscar uma maior qualidade de vida. Entretanto, para a finalidade deste livro, refugiados ambientais são definidos como aquelas pessoas forçadas a deixar seu habitat natural, temporária ou permanentemente, por causa de uma marcante perturbação ambiental (natural e/ou desencadeada pela ação humana), que colocou em risco sua existência e/ou seriamente afetou sua qualidade de vida. Por "perturbação ambiental", nessa definição, entendemos quaisquer mudanças físicas, químicas, e/ou biológicas no ecossistema (ou na base de recursos), que o tornem, temporária ou permanentemente, impróprio para sustentar a vida humana. De acordo com esta definição, pessoas deslocadas por razões políticas ou por conflitos civis e migrantes em busca de melhores empregos (por motivos estritamente econômicos) não são consideradas refugiados ambientais.

Existem três grandes categorias de refugiados ambientais. Primeiro, há aqueles que foram deslocados temporariamente

\footnotetext{
${ }^{14}$ Os princípios orientadores relativos aos deslocados internos foram elaborados por uma equipe internacional de especialistas em direito em colaboração com agências internacionais e ONGs. O texto integral está disponível para consulta em: <http://www2.ohchr.org/english/issues/idp/GPPortuguese.pdf>. Acesso em: 29 jul. 2014. Tais princípios foram apresentados pelo Representante Especial do Secretário-Geral para Deslocados Internos em 1998 (E/CN.4/1998/53/Add.2) e posteriormente foram reconhecidos em Resoluções da Comissão de Direitos Humanos (E/CN.4/RES/2001/54), do Conselho Econômico e Social ECOSOC (2003/5) e da Assembleia Geral da ONU (A/RES/56/164 de 2001). RAMOS, Érika Pires. Refugiados Ambientais: Em Busca De Reconhecimento Pelo Direito Internacional.- São Paulo : E. P. Ramos, 2011.p. 81
} 
QUEIROZ, Yury Augusto dos Santos; GARCIA, Denise Schmitt Siqueira. Deslocados ambientais: um conceito ainda desconhecido. Revista Eletrônica Direito e Política, Programa de Pós-Graduação Stricto Sensu em Ciência Jurídica da UNIVALI, Itajaí, v.10, n.1, edição especial de 2015. Disponível em: www.univali.br/direitoepolitica - ISSN 1980-7791.

por causa de um stress ambiental. [...] A segunda categoria de refugiados ambientais compreende aqueles que tiveram de ser permanentemente deslocados e restabelecidos em uma nova área. [...] A terceira categoria de refugiados ambientais é constituída de indivíduos ou grupos de pessoas que migram de seu habitat original, temporária ou permanentemente, para um novo dentro de suas fronteiras nacionais, ou no exterior, em busca de uma melhor qualidade de vida ${ }^{15}$.

Como pode ser observado para El-Hinnawi os deslocados ambientais estão inseridos diretamente dentro da categoria refugiados ambientais. Por sua vez, Myers (1993) entende que refugiados ambientais são aquelas pessoas que:

[...] já não podem ganhar uma vida segura em suas pátrias por causa de secas, erosão do solo, desertificação, e outros problemas ambientais. Em seu desespero, elas sentem que não têm outra alternativa senão a de procurar refúgio noutros países, mesmo que isto seja uma alternativa perigosa $^{16}$

Todavia Myers não faz qualquer distinção entre deslocados e refugiados ambientais, muito embora da leitura dos conceitos surja o seguinte entendimento: quando a pessoa atravessa o limite definido de seu país para

\footnotetext{
15"'In a broad sense, all displaced people can be described as environmental refugees, having been forced to leave their original habitat (or having left voluntarily) to protect themselves from harm and/or to seek a better quality of life. However, for the purpose of this book, environmental refugees are defined as those people who have been forced to leave their traditional habitat, temporarily or permanently, because of a marked environmental disruption (natural and/or triggered by people) that jeopardized their existence and/or seriously affected the quality of their life. By "environmental disruption" in this definition is meant any physical, chemical and/or biological changes in the ecosystem (or the resource base) that render it, temporarily or permanently, unsuitable to support human life. According with this definition, people displaced for political reasons or by civil strife and migrants seeking better jobs purely on economics ground are not considered environmental refugees. There are three broad categories of environmental refugees. First, there are those who have been temporarily displaced because of an environmental stress. [...] The second category of environmental refugees comprises those who have to be permanently displaced and re-settled in a new area. [...] The third category of environmental refugees consists of individuals or groups of people who migrate from their original habitat, temporarily or permanently, to a new one within own national boundaries, or abroad, in search of a better quality of life." EL-HINNAWI, Essam.Environmental Refugees.Nairobi: United Nations Environment Programme (UNEP), 1985, p. 04-05. In: RAMOS, Érika Pires. Refugiados Ambientais: Em Busca De Reconhecimento Pelo Direito Internacional. - São Paulo : E. P. Ramos, 2011. p.77.

${ }^{16}$ MYERS, Norman. Environmental Refugees in a globally warmed world. In: BioScience. Vol. 43, n. 11, dez 1993. p. 752. "They are people who can no longer gain a secure livelihood in their erstwhile homelands because of drought, soil erosion, desertification, and other environmental problems. Int their desperation, they feel they have no alternative but to seek sanctuary elsewhere, however hazardous the attempt.".
} 
QUEIROZ, Yury Augusto dos Santos; GARCIA, Denise Schmitt Siqueira. Deslocados ambientais: um conceito ainda desconhecido. Revista Eletrônica Direito e Política, Programa de Pós-Graduação Stricto Sensu em Ciência Jurídica da UNIVALI, Itajaí, v.10, n.1, edição especial de 2015. Disponível em: www.univali.br/direitoepolitica - ISSN 1980-7791.

outro ela será considerada refugiada, por outro lado se deslocar-se apenas internamente esta deverá ser definida como deslocado ambiental.

Mas estaria correta esta primeira constatação? Na visão de Cournil o importante não é o termo que se usa e sim a sua abrangência, de tal modo além do termo refugiados ambientais e deslocados ambientais o autor elenca ainda:

Réfugiés écologiques", migrants ou "réfugiés de l'environnement", "réfugie's climatiques", "éco-réfugiés", "personnes déplacées en raison d'une catastrophe naturelle", "exodes écologiques", etc., nombreux sont les termes qui traduisent l'exil, la migration ou le déplacement en raison

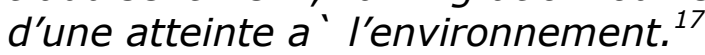

Muito embora a intenção dos autores seja de aprimorar o conceito e dessa forma contribuir com aqueles que dele ainda terão de se utilizar, ainda não há um consenso a demonstrar especificamente quem são os deslocados ambientais e refugiados ambientais, e se estão inseridos em uma categoria geral ou específica.

Para elucidar um pouco mais a discussão, Richard Black, um dos mais críticos autores no debate sobre a temática dos "refugiados ambientais", ressalta as dificuldades decorrentes da pluralidade de definições e tipologias que, segundo ele, revela a falta de precisão e a pouca utilidade nas tentativas de descrição do fenômeno propostas pelos autores, dentre eles os mencionados em linhas anteriores (El-Hinnawi, Jacobson e Myers) ${ }^{18}$ :

[...] There are abundant typologies of 'environmental refugees' and 'environmental migrants', but little agreement on, or understanding of what these categories might really mean. Practical concern with the plight of poor people leaving fragile environments has not translated into hard evidence of the extent or fundamental causes of their problems. Moreover, there remains a danger that academic

\footnotetext{
${ }^{17}$ COURNIL, Christel. Les réfugiés écologiques: Quelle(s) protection(s), quel(s) tatut(s)? In: Revue du Droit Public. p. 1038. n.4, 2006. 'Refugiados ecológicos', migrantes ou 'refugiados do ambiente', 'refugiados do clima', 'eco-refugiados', 'pessoas deslocadas em razão de uma catástrofe natural', 'êxodo ecológico', etc., são termos que refletem o exílio, a migração ou deslocamento em razão de algo que atente ao meio ambiente (tradução do autor).
}

${ }^{18}$ RAMOS, Érika Pires. Refugiados Ambientais: Em Busca De Reconhecimento Pelo Direito Internacional.- São Paulo : E. P. Ramos, 2011.p. 81. 
QUEIROZ, Yury Augusto dos Santos; GARCIA, Denise Schmitt Siqueira. Deslocados ambientais: um conceito ainda desconhecido. Revista Eletrônica Direito e Política, Programa de Pós-Graduação Stricto Sensu em Ciência Jurídica da UNIVALI, Itajaí, v.10, n.1, edição especial de 2015. Disponível em: www.univali.br/direitoepolitica - ISSN 1980-7791.

and policy writing on 'environmental refugees' has more to do with bureaucratic agendas of international organizations and academics than with any real theoretical or empirical insight. ${ }^{19}$.

Nessa mesma linha de pensamento, Stephen Castles argumenta que a expressão "refugiados ambientais" é simplista e equivocada e induz a uma "monocausalidade" que raramente pode ser averiguada na prática. Além disso, adiciona que a denominação é restritiva em vista da complexidade de causas e formas de deslocamento humano, bem como é inadequada ante o regime de proteção internacional vigente:

A reasonable conclusion from this research literature is therefore that the notion of the 'environmental refugee' is misleading and does little to help us understand the complex processes at work in specific situations of impoverishment, conflict and displacement. This does not mean, however, that environmental factors are unimportant in such situations. Rather they are part of complex patterns of multiple causality, in which natural and environmental factors are closely linked to economic, social and political ones. This is where we need much more research and better understanding, if we are to address the root causes of forced migration $^{20}$.

Dando continuidade às críticas sobre a terminologia "refugiados ambientais", temos o estudo Climate Change Refugees and Migration onde diz o seguinte:

\footnotetext{
${ }^{19}$ Há abundantes tipologias de 'refugiados ambientais' e 'migrantes ambientais', mas pouco acordo ou compreensão do que essas categorias podem realmente significar. A preocupação prática com a situação das pessoas pobres saindo de ambientes frágeis não se traduz em provas concretas da extensão ou em causas fundamentais dos seus problemas. Além disso, há ainda o perigo de que os escritos acadêmicos e de políticas em 'refugiados ambientais' tenham mais a ver com agendas burocráticas de organizações internacionais e acadêmicas do que com qualquer conhecimento teórico ou empírico real. (tradução do autor). BLACK, Richard. Environmental refugees: myth or reality? UNHCR Working Paper no 34, Geneva, March 2001, p. 13-14.
}

${ }^{20}$ A conclusão razoável a partir desta literatura de pesquisa é, portanto, que a noção de "refugiado ambiental" é enganosa e pouco faz para nos ajudar a compreender os complexos processos de trabalho em situações específicas de empobrecimento, conflitos e deslocamentos. Isso não significa, porém, que fatores ambientais não são importantes nestas situações. Ao contrário, eles fazem parte de padrões complexos de causalidade múltipla, em que os fatores naturais e ambientais estão intimamente ligados à natureza econômica, social e política. Isto é onde precisamos de muito mais pesquisa e melhor compreensão, se queremos combater as causas da migração forçada (tradução do autor). CASTLES, Stephen. Environmental change and forced migration: making sense of the debate. UNHCR Working Paper no 70, Geneva, October 2002, p. 5. Disponível em: <http://www.unhcr.org/research/RESEARCH/3de344fd9.pdf>. Acesso em: 11 set. 2014. 
QUEIROZ, Yury Augusto dos Santos; GARCIA, Denise Schmitt Siqueira. Deslocados ambientais: um conceito ainda desconhecido. Revista Eletrônica Direito e Política, Programa de Pós-Graduação Stricto Sensu em Ciência Jurídica da UNIVALI, Itajaí, v.10, n.1, edição especial de 2015. Disponível em: www.univali.br/direitoepolitica - ISSN 1980-7791.

Others suggest "environmentally displaced person" and "environmentally induced migration". They argue that it is not only inadvisable to use the word "refugee", but that it is often impossible to specifically pinpoint the impact of climate change on a person's decision to move, and that "environmental" would therefore be the better choice.

Not everyone agrees. Certain experts claim that "environmental" is too broad. Industrial accidents, for instance, are environmental, but rarely related to climate change. The same holds for most nuclear catastrophes, or the construction of a dam. All these phenomena are possible push-factors of displacement, all are environmental, but not all of them are necessarily linked to climate change. Most importantly, however: Many fall under already existing protection schemes and don't have to be covered by new mechanisms.

Also, a number of politicians and specialists argue that "refugee" makes it much clearer than "migrant" that we are talking about (planned or un-planned) forced rather than voluntary movements, taking place due to (slow-onset or sudden) external factors ${ }^{21}$.

Em que pese todos os conceitos apresentados, bem como todas as críticas doutrinárias sobre as tentativas de se chegar a um consenso, o mais importante é que se tenha em mente o fato de que tanto no caso dos refugiados quanto nos casos dos deslocados ambientais o fator primordial para mudança, migração e deslocamento se deve as inúmeras alterações climáticas que o planeta vem sofrendo e por este motivo independentemente do nome ou conceito devem ser

21 Outros sugerem "pessoa ambientalmente deslocada" e "migração induzida ambiental". Eles argumentam que não é só desaconselhável o uso da palavra "refugiado", mas que muitas vezes é impossível identificar especificamente o impacto da mudança climática sobre a decisão de uma pessoa para se mover, e que "ambiental", portanto, seria a melhor escolha.

Nem todos concordam. Alguns especialistas afirmam que "ambiental" é muito amplo. Acidentes de trabalho, por exemplo, são ambientais, mas raramente relacionada à mudança climática. O mesmo vale para a maioria das catástrofes nucleares, ou a construção de uma barragem. Todos esses fenômenos são possíveis de provocar fatores de deslocamento, todos são ambientais, mas nem todos estão necessariamente ligadas às mudanças climáticas. O mais importante, no entanto: Muitos caem no âmbito de regimes de proteção já existentes e não tem por objetivo novos mecanismos.

Além disso, um número de políticos e especialistas argumentam que "refugiado" soa muito mais claro que "migrante" do qual estamos falando (planejada ou não-planejada) ao invés de movimentos voluntários, ocorrendo devido a (graduais ou súbitos) fatores externos. (tradução do autor). GREENS EFA - Position Paper - Climate Change Refugees and Migration. Redigida por Hélène Flautre, Jean Lambert, Ska Keller and Barbara Lochbihler. Adotado em Maio de 2013. Disponível em: <http://barbara-lochbihler.de/cms/upload/PDF_2013/Greens_EFA_Position Paper_Climate_ChangeRefugeesandMigration.pdf >. Acesso em: 26 Set. 2014. 
QUEIROZ, Yury Augusto dos Santos; GARCIA, Denise Schmitt Siqueira. Deslocados ambientais: um conceito ainda desconhecido. Revista Eletrônica Direito e Política, Programa de Pós-Graduação Stricto Sensu em Ciência Jurídica da UNIVALI, Itajaí, v.10, n.1, edição especial de 2015. Disponível em: www.univali.br/direitoepolitica - ISSN 1980-7791.

garantidas aos afetados, o mínimo existencial, e com base nesse entendimento, passemos ao estudo do Projet De Convention Relative Au Statut Internationaldes Déplacés Environnementaux que é um dos projetos pioneiros sobre o tema e sobre as proteções e garantias que deveriam ser oferecidas aos afetados pelas mudanças climáticas e que precisam deixar seus lares para outro país ou região.

\section{DESLOCADOS AMBIENTAIS NO CONCEITO DO PROJET DE CONVENTION RELATIVE AU STATUT INTERNATIONALDES DÉPLACÉS ENVIRONNEMENTAUX}

Com fulcro de criar uma legislação internacional específica e abrangente foi elaborado por um grupo de especialistas da Faculdade de Direito e de Ciências Econômicas da Universidade de Limoges, na França, o Projet De Convention Relative Au Statut Internationaldes Déplacés Environnementaux ${ }^{22}$, em tradução livre: Projeto De Convenção Relativa Ao Estatuto Internacional dos Deslocados Ambientais. Entre os autores estão Michel Prieur, Jean-Pierre Marguénaud, Gerárd Monédiaire, Julien Betáille, Bernard Drobenko, Jean-Jacques Gouguet, Jean-Marc Lavieille, Séverine Nadaud E Damien Roets.

Em palestra realizada no ano de 2010 no Congresso Internacional "O novo no direito ambiental por Michel Prieur", no Auditório da Procuradoria Regional da República, em São Paulo, Michel Prieur indica que entre as bases para o projeto de convenção internacional sobre deslocados ambientais, estão: art. 11.1. do Pacto Internacional sobre direito econômicos, sociais e culturais (1966); Resolução da Assembleia Geral das Nações Unidas sobre assistência humanitária às vítimas das catástrofes naturais (45/100 - 1988); Princípios 18 e

\footnotetext{
${ }^{22}$ Texto publicado na Revue Européenne du Droit de L'Environnement, n 4/2008, p. 381-

393. Versão original em francês.Projeto de Convenção elaborado pelo CRIDEAU (Centre de R echerche Interdisciplinaire en Droit de I'Environnement, de l'Aménagement et de I'Urbanisme) e pel o CRDP (Centre de Recherche sur les Droits de la Personne), equipes temáticas do OMIJ (Observat oire des Mutations Institutionnelles et juridiques), Faculdade de Direito e de Ciências Econômica s da Universidade de Limoges, com a participação do CIDCE (Centre International de Droit C omparé de l'Environnement). Disponível em em: <http://www.cidce.org/pdf/APRESENTA\%C3\%87\%C3\%830\%20DO\%20PROJETO\%20DE\%20CONV EN\%C3\%87\%C3\%830\%20RELATIVA\%20AO\%20ESTATUTO\%20INTERNACIONAL.pdf >. Acesso em: 24 Set. 2014.
} 
QUEIROZ, Yury Augusto dos Santos; GARCIA, Denise Schmitt Siqueira. Deslocados ambientais: um conceito ainda desconhecido. Revista Eletrônica Direito e Política, Programa de Pós-Graduação Stricto Sensu em Ciência Jurídica da UNIVALI, Itajaí, v.10, n.1, edição especial de 2015. Disponível em: www.univali.br/direitoepolitica - ISSN 1980-7791.

27 da Declaração (1992), relativos à assistência ecológica e à solidariedade internacional; e Conferência sobre a Prevenção de Catástrofes Naturais ${ }^{23}$.

Nas primeiras linhas do texto base onde se enumeram os fatores que deram ensejo ao projeto, os autores colocam como um dos principais geradores o fato de:

Considérant que, malgré les nombreux instruments internationaux visant à proteger l'environnement, il n'existe, dans l'état actuel du droit international applicable aux réfugiés, aucun instrument spécifique prévoyant la situation d'ensemble des déplacés environnementaux et pouvant être appliqué et invoqué en leur faveur ${ }^{24}$.

Posteriormente se passa a expor o objetivo do projeto que é "contribuir para garantir direitos aos deslocados ambientais e organizar seu acolhimento e seu eventual retorno, em aplicação ao princípio da solidariedade ${ }^{25 \prime \prime}$.

Apesar dos inúmeros conceitos apresentados durante todo o trabalho de pesquisa não foi possível encontrar para os deslocados ambientais um conceito melhor do que o exarado pelo projeto de PRIEUR, vejamos:

On appelle « déplacés environnementaux » les personnes physiques, les familles et les populations confrontées à un bouleversement brutal ou insidieux de leur environnement portant inéluctablement atteinte à leurs conditions de vie et les forçant à quitter, dans l'urgence ou dans la durée, leurs

\footnotetext{
${ }^{23}$ MENDES, João. "Congresso Internacional "O novo no direito ambiental por Michel Prieur". Disponível em: <http://neiarcadas.wordpress.com/2010/09/03/congressointernacionalmichelprieur/>. Acesso em: 24 Set. 2014.
}

24 PRIEUR, Michel. Projet De Convention Relative Au Statut Internationaldes Déplacés Environnementaux "Considerando que, a despeito dos numerosos instrumentos internacionais visando a proteção do meio ambiente, não existe, no estado atual do direito internacional aplicável aos refugiados, nenhum instrumento específico prevendo a situação do conjunto dos deslocados ambientais e podendo ser aplicado e invocado em seu favor". Disponível em: <http://www.cidce.org/pdf/Projet\%20de\%20convention\%20relative\%20au\%20statut\%20internati onal\%20des\%20d\%C3\%A9plac\%C3\%A9s\%20environnementaux.pdf>. Acesso em: 16 Ago. 2014.

\footnotetext{
${ }^{25}$ PRIEUR, Michel. Projeto De Convenção Relativa Ao Estatuto Internacional dos Deslocados Disponível em português em: <http://www.cidce.org/pdf/APRESENTA\%C3 $\% 87 \%$ C3\%830\%20DO\%20PROJETO\%20DE\%20CONVEN\%C3\%87\%C3\%830\%20RELATIVA\%20A O\%20ESTATUTO\%20INTERNACIONAL.pdf>. Acesso em: 24 Set. 2014.
} 
QUEIROZ, Yury Augusto dos Santos; GARCIA, Denise Schmitt Siqueira. Deslocados ambientais: um conceito ainda desconhecido. Revista Eletrônica Direito e Política, Programa de Pós-Graduação Stricto Sensu em Ciência Jurídica da UNIVALI, Itajaí, v.10, n.1, edição especial de 2015. Disponível em: www.univali.br/direitoepolitica - ISSN 1980-7791.

lieux habituels de vie et conduisant à leur réinstallation et à leur relogement ${ }^{26}$.

Ao longo do projeto os autores tratam de forma rica e enumeram alguns detalhes que antes eram deixados de lado, como por exemplo, ainda quando conceituando os deslocados ambientais é feita uma conceituação também das formas de deslocamento, se temporárias ou definitivas, e por mais que do próprio entendimento literal da palavra se tenha o conceito destas categorias, os autores buscam não deixar margem a entendimentos vagos e que possam dificultar a aplicação futura dos termos.

Conforme o capítulo dois do projeto todo deslocado ambiental teria direito a garantias básicas como ajuda alimentar, água, habitação e assistência médica entre outros direitos fundamentais que hoje não são garantidos haja vista a escassez de uma legislação firmada a nível mundial sobre o tema.

Dentre as garantias que fogem ao básico elenca-se que os deslocados temporários $^{27}$ têm direito ao alojamento em segurança, à reinstalação, ao retorno e à permanência prolongada. Já os deslocados definitivos têm direito ao realojamento e à nacionalidade ${ }^{28}$. Por sua vez, as famílias e as populações têm direitos específicos à preservação de sua unidade e às minorias.

\footnotetext{
26 Se designa « deslocados ambientais » as pessoas físicas, as famílias e as populações confrontadas a um desastre brutal ou gradual em seu ambiente afetando inelutavelmente suas condições de vida e Ihes forçando a deixar, com urgência ou no seu decorrer, seus lugares habituais de vida e requerendo sua relocação ou realojamento. (tradução do autor) CRIDEAU/CRDP/UNIVERSITE DE LIMOGES/CIDCE. Projet de Convencion Relative au Statut International des "Desplacés Environnementaux". Deuxième version. Montaigut, commune de St Yrieix la Perche, Limousin (FRANCE), le 31 mai 2010. Disponível em: <http://www.cidce.org/pdf/Projet\% 20de\%20convention\%20relative\%20au\%20statut\%20 international\%20des\%20d\%C3\%A9plac\%C3\%A9s\%20environnementaux\%20\%28deuxi\%C3\%A8 me\%20version\%29.pdf>. Acesso em: 25 Set. 2014.
}

27"Todo deslocamento necessário gerado por um desastre ambiental que deixa aberta a perspectivaa de um retorno à curto ou médio prazo". PRIEUR, Michel. Projeto De Convenção Relativa Ao Estatuto Internacional dos Deslocados Disponível em português em: <http://www.cidce.org/pdf/APRESENTA\%C3\%87\%C3\%830\%20DO\%20PROJETO\%20DE\%20CONV EN\%C3\%87\%C3\%830\%20RELATIVA\%20AO\%20ESTATUTO\%20INTERNACIONAL.pdf >. Acesso em: 24 Set. 2014.

28"Todo deslocamento necessário gerado por um desastre ambiental que suprime toda perspectiva de retorno à longo ou muito longo prazo". PRIEUR, Michel. Projeto De Convenção Relativa Ao Estatuto Internacional dos Deslocados Disponível em português em: <http://www.cidce.org/pdf/APRESENTA\%C3\%87\%C3\%830\%20DO\%20PROJETO\%20DE\%20CONV EN\%C3\%87\%C3\%830\%20RELATIVA\%20AO\%20ESTATUTO\%20INTERNACIONAL.pdf >. AcesSO em: 24 Set. 2014. 
QUEIROZ, Yury Augusto dos Santos; GARCIA, Denise Schmitt Siqueira. Deslocados ambientais: um conceito ainda desconhecido. Revista Eletrônica Direito e Política, Programa de Pós-Graduação Stricto Sensu em Ciência Jurídica da UNIVALI, Itajaí, v.10, n.1, edição especial de 2015. Disponível em: www.univali.br/direitoepolitica - ISSN 1980-7791.

Já para administrar mundialmente os deslocados ambientais segundo o projeto da convenção deveria ser criada uma agência mundial para os deslocados ambientais - AMDA, que teria por missão principal conduzir os trabalhos de prospeç̧ão sobre a evolução do fenômeno dos deslocados ambientais, assim como avaliar políticas nacionais e internacionais, mobilizar eventos, avaliar programas e dar suporte aos deslocados nos diferentes pontos do globo.

Em suma o projeto demonstra que somente através de um estudo detalhado e de uma abordagem global será possível obter uma solução para o problema dos deslocados ambientais que segundo a ACNUR no relatório Tendências Globais 2008 contabilizou 42 milhões de pessoas forçadamente deslocadas, das quais 15,2 milhões são refugiados, 827 mil solicitantes de asilo e 26 milhões deslocados internos, sendo que aproximadamente 25 milhões receberam proteção ou assistência pelo ACNUR, dos quais 10,5 milhões de refugiados e 14,4 milhões de deslocados internos.

Apesar do estudo do conceito de deslocado ambiental ser o tema central deste trabalho, é primordial e indispensável que se tenha em mente que seu reconhecimento pela comunidade internacional só se dará através da elaboração de tratados regionais ou uma convenção em escala global, e ainda assim seria preciso a formatação de uma agenda de compromissos entre os Estados que objetivasse o cumprimento de ações que minimizem as causas que originam tais migrantes e que estão diretamente relacionadas à degradação ambiental, bem como à concepção de instrumentos que responsabilizem aos seus causadores ${ }^{29}$.

Portanto além da procura em amenizar os desastres ambientais é preciso que se obtenham meios para atender as pessoas afetadas por eles, fato que infelizmente vem sendo esquecido por muitas governanças a nível mundial, sendo uma das provas desta negligência o fato de que apesar de elaborado em 2008 o projeto da convecção ainda não assinado por nenhum país.

\footnotetext{
${ }^{29}$ JESUS, Thiago Schneider de. Dissertação para Mestrado da Universidade de Caxias do Sul/RS. Um novo desafio ao direito: deslocados/migrantes ambientais reconhecimento, proteção e solidariedade. Caxias do SUL. RS. $2009 . \quad$ Disponível em:<http://tede.ucs.br/tde_arquivos/2/TDE-2009-07-02T133513Z-

285/Publico/Dissertacao\%20Tiago\%20Schneider\%20de\%20Jesus.pdf>. Acesso em: 01 Set. 2014.
} 
QUEIROZ, Yury Augusto dos Santos; GARCIA, Denise Schmitt Siqueira. Deslocados ambientais: um conceito ainda desconhecido. Revista Eletrônica Direito e Política, Programa de Pós-Graduação Stricto Sensu em Ciência Jurídica da UNIVALI, Itajaí, v.10, n.1, edição especial de 2015. Disponível em: www.univali.br/direitoepolitica - ISSN 1980-7791.

\section{CONSIDERAÇÕES FINAIS}

Como restou demonstrado ao longo deste estudo apesar da crescente discussão que vem sendo realizada acerca dos descolados ambientais não foi possível a conceptualização do tema, pois os autores assim como seus pontos de visão divergem em muitos aspectos. Todavia após este estudo é possível perceber que apesar das disposições contrárias todos os autores afirmam a necessidade urgente da criação de uma legislação internacional que possa resguardar os direitos dos deslocados, refugiados, migrantes e/ou imigrantes ambientais.

Nessa seara temos como um dos principais projetos o de autoria de Michel Prieur em parceria com outros reconhecidos estudiosos e críticos do tema, o denominado Projet De Convention Relative Au Statut Internationaldes Déplacés Environnementaux ${ }^{30}$ que pormenoriza diversas situações e trata dos principais direitos que os deslocados ambientais deveriam ter, não só pela situação em que em se encontram, mas pelo fato de que são direitos e garantias fundamentais tais como: alimentação, água, identidade, moradia, entre outras.

A busca pelo conceito nunca chegará ao fim, isto é certo. Por outro lado é imperioso que se chegue a um consenso internacional sobre o tema, haja vista que sua falta não só prejudica os deslocados ambientais como atrapalha os países receptores ou as regiões receptoras nos casos dos deslocados internos, que sem base legal se veem perdidos em um mar de legislações não específicas, utilizando-se da analogia para tomar medidas e providenciar soluções que muitas das vezes só amenizam o problema.

Por fim, este trabalho entende como deslocados ambientais todo ser humano que se vê obrigado a deslocar-se de uma região para outra, de um país para outro ou

30 Texto publicado na Revue Européenne du Droit de L'Environnement, n 4/2008, p. 381393. Versão original em francês.Projeto de Convenção elaborado pelo CRIDEAU (Centre de $R$ echerche Interdisciplinaire en Droit de I'Environnement, de I'Aménagement et de I'Urbanisme) e pel o CRDP (Centre de Recherche sur les Droits de la Personne), equipes temáticas do OMIJ (Observat oire des Mutations Institutionnelles et juridiques), Faculdade de Direito e de Ciências Econômica s da Universidade de Limoges, com a participação do CIDCE (Centre International de Droit C omparé de l'Environnement). Disponível em português em: $<$ http://www.cidce.org/pdf/APRESENTA\%C3

\%87\%C3\%830\%20DO\%20PROJETO\%20DE\%20CONVEN\%C3\%87\%C3\%830\%20RELATIVA\%20A O\%20ESTATUTO\%20INTERNACIONAL.pdf>. Acesso em: 24 Set. 2014. 
QUEIROZ, Yury Augusto dos Santos; GARCIA, Denise Schmitt Siqueira. Deslocados ambientais: um conceito ainda desconhecido. Revista Eletrônica Direito e Política, Programa de Pós-Graduação Stricto Sensu em Ciência Jurídica da UNIVALI, Itajaí, v.10, n.1, edição especial de 2015. Disponível em: www.univali.br/direitoepolitica - ISSN 1980-7791.

mesmo de continente, não é possível fazer a diferenciação entre os refugiados e deslocados ambientais de uma forma ampla, pois a situação de ambos na maioria dos casos é equivalente, a única divisão possível é em relação aos deslocados internos e externos.

\section{REFERÊNCIAS DAS FONTES CITADAS}

BETTS, Alexander. Towards a 'soft law' framework for theprotectionofvulnerablemigrants. UNHCR WorkingPaper no 162, p. 23. Disponível em: <http://www.un.org/esa/population/meetings/seventhcoord2008/Betts_SoftLaw _Paper.pdf.> Acesso em: 29 jul 2014.

BLACK, Richard. Environmental refugees: mythor reality?UNHCR WorkingPaper no 34, Geneva, March 2001.

CASTLES, Stephen. Environmental changeandforcedmigration: makingsenseofthe debate.UNHCR WorkingPaper no 70, Geneva, October 2002, p. 5. Disponível em: <http://www.unhcr.org/research/RESEARCH/3de344fd9.pdf>. Acesso em: 11 set. 2014.

CAVARZERE, Thelma Thais. Direito internacional da pessoa humana: a circulação internacional de pessoas. Rio de Janeiro: Renovar, 1995, p. 09.

CONVENÇÃO DE GENEBRA. Série Tratados da ONU, No 2545, Vol. 189, p. 137. Disponível em: <http://www.acnur.org/t3/fileadmin/scripts/doc.php?file=t3/fileadmin/Document os/portugues/BDL/Convencao_relativa_ao_Estatuto_dos_Refugiados>. Acesso em: 26 Set. 2014

COURNIL, Christel. Lesréfugiésécologiques: Quelle(s) protection(s), quel(s) tatut(s)? In: RevueduDroit Public. p. 1038. n.4, 2006.

CRIDEAU/CRDP/UNIVERSITÉ DE LIMOGES/CIDCE. Projet de ConvencionRelativeauStatutInternationaldes

"DesplacésEnvironnementaux".Deuxièmeversion. Montaigut, commune de StYrieixla Perche, Limousin (FRANCE), le 31 mai 2010. Disponível em: <http://www.cidce.org/pdf/Projet\%20de\%20convention\%20relative\%20au\%20s tatut\%20international\%20des\%20d\%C3\%A9plac\%C3\%A9s\%20environnementa ux\%20\%28deuxi\%C3\%A8me\%20version\%29.pdf>. Acesso em: 25 Set. 2014.

EL-HINNAWI, Essam.Environmental Refugees. Nairobi: United Nations Environment Programme (UNEP), 1985, p. 04-05. In: RAMOS, Érika Pires. 
QUEIROZ, Yury Augusto dos Santos; GARCIA, Denise Schmitt Siqueira. Deslocados ambientais: um conceito ainda desconhecido. Revista Eletrônica Direito e Política, Programa de Pós-Graduação Stricto Sensu em Ciência Jurídica da UNIVALI, Itajaí, v.10, n.1, edição especial de 2015. Disponível em: www.univali.br/direitoepolitica - ISSN 1980-7791.

Refugiados Ambientais: Em Busca De Reconhecimento Pelo Direito Internacional. - São Paulo : E. P. Ramos, 2011. p.77.

GREENS EFA - Position Paper- ClimateChangeRefugeesandMigration. Redigida por HélèneFlautre, Jean Lambert, Ska Keller and Barbara Lochbihler. Adotado em Maio de 2013. Disponível em: <http://barbaralochbihler.de/cms/upload/PDF_2013/Greens_EFA_Position

Paper_Climate_ChangeRefugeesandMigration.pdf > . Acesso em: 26 Set. 2014.

JESUS, Thiago Schneider de. Dissertação para Mestrado da Universidade de Caxias do Sul/RS. Um novo desafio ao direito: deslocados/migrantes ambientais reconhecimento, proteção e solidariedade. Caxias do SUL. RS. 2009. Disponível em:<http://tede.ucs.br/tde_arquivos/2/TDE-2009-0702T133513Z-

285/Publico/Dissertacao\%20Tiago\%20Schneider\%20de\%20Jesus.pdf $>$. Acesso em: 01 Set. 2014.

MENDES, João. "Congresso Internacional "O novo no direito ambiental por Michel Prieur". Disponível em: <http://neiarcadas. wordpress.com/2010/09/03/congressointernacionalmiche Iprieur/>. Acesso em: 24 Set. 2014.

MYERS, Norman. Environmental Refugees in a globallywarmed world. In: BioScience. Vol. 43, n. 11, dez 1993.

PRIEUR, Michel. Projet De ConventionRelativeAuStatutInternationaldesDéplacésEnvironnementaux Disponível em: <http://www.cidce.org/pdf/Projet\%20de\%20convention\%20relative\%20au\%20s tatut\%20international\%20des\%20d\%C3\%A9plac\%C3\%A9s\%20environnementa ux.pdf>. Acesso em: 16 Ago. 2014.

PRIEUR, Michel. Projeto De Convenção Relativa Ao Estatuto Internacional dos Deslocados Disponível em português em: <http://www.cidce.org/pdf/APRESENTA\%C3\%87\%C3\%830\%20DO\%20PROJETO $\% 20$ DE $\% 20$ CONVEN\%C3\%87\%C3\%830\%20RELATIVA\%20AO\%20ESTATUTO\% 20INTERNACIONAL.pdf>. Acesso em: 24 Set. 2014.

RAMOS, Érika Pires. Refugiados Ambientais: Em Busca De Reconhecimento Pelo Direito Internacional.- São Paulo : E. P. Ramos, 2011.p. 81.

Submetido em: Setembro/2014

Aprovado em: Outubro/2014 